\title{
University Students' Knowledge, Attitude and Practice (KAP) of Endocrine Disrupting Chemicals (EDCs): The Use of Selected Plastic-Type Food Contact Materials in Kuala Terengganu
}

\author{
${ }^{1}$ Hui, CK, ${ }^{2}$ Kamarudin, KS \& ${ }^{1}$ Yusof HM* \\ ${ }^{1}$ School of Food Science and Technology, Universiti Malaysia Terengganu, 21030 Kuala Terengganu, Malaysia, \\ ${ }^{2}$ Department of Fundamental Knowledge and Liberal Education, Centre for Fundamental and Liberal \\ Education, Universiti Malaysia Terengganu, 21030 Kuala Terengganu, Malaysia.
}

\begin{abstract}
This study determined levels of student KAP regarding the use of Plastic-Type Food Contact Materials (PTFCMs) with regard to their exposure to Endocrine Disrupting Chemicals (EDCs) and EDC type, as well as modulating factors affecting both exposure and use. A cross-sectional study that involved 150 university students in Kuala Terengganu was carried out between July and September 2015. Results showed that $84.0 \%$ of students had low knowledge levels while $90.0 \%$ had a 'fair' attitude classification. Most respondents commonly used polypropylene (PP) as either liquid or food containers. The greatest modulator was less cost.

Conclusion: Student knowledge, attitude and practice with respect to EDCs and PTFCMs require improvement to minimize adverse health effects. Hence, government agencies should address the need for public education programs regarding EDCs contained in PTFMCs to advance knowledge, attitude and practice, and thereby help prevent adverse developmental outcomes.
\end{abstract}

Keywords: Endocrine disrupting chemicals, plastic-type food contact materials, Usage, Migration.

\section{Introduction}

The present study assessed student KAP to determine their understanding of a particular topic (knowledge) in addition to beliefs (attitude) that affect observable actions (practice) and health status (FAO, 2014). The authors also investigated potential routes of EDC exposure as well as EDC type by citing to previous studies of conditions that facilitate EDC migration of from PTFCMs. The 'International Programme on Chemical Safety' (IPCS) defined endocrine disruptors and potential EDCs as follows:

"An endocrine disruptor is an exogenous substance or mixture that alters function(s) of the endocrine system and consequently causes adverse effects in an intact organism, or its progeny, or (sub) populations. A potential endocrine disruptor is an exogenous substance or mixture that possesses properties that might be expected to lead to endocrine disruption in an intact organism, or its progeny, or (sub) populations" (IPCS, 2002).

EDCs initially received attention as causes for reproductive and developmental anomalies. They have also received even more notice due to concerns for deleterious effects that also cause cardiovascular disease, obesity, diabetes, cancers and neurological problems (Muncke, 2011). There is additional evidence indicating that EDCs not only negatively affect an exposed individual but also the latter's offspring and subsequent generations (Patisaul and Adewale, 2009).

Sources of EDC exposure are globally endemic and diverse, noting that chemical components of plastics leaching into foodstuffs constitute the majority (Shaw, 2009). Routes of EDC exposure from PTFCMs area growing concern. These include plastic cutlery, dishes, bottles and food containers, etc. Commonly used plastic bottles include polyethylene terephthalate (PET), polycarbonate (PC), and Tritan ${ }^{\mathrm{TM}}$-ach one is a source of EDCs (Bach et al. 2012; Guart et al. 2013). Surprisingly, the consumption of canned food and beverages also exposes individuals to bisphenol-A (BPA), a type of EDC. This is due to epoxy resins used as a food contact lacquer coating within cans (Sungur et al. 2014). EDCs within PTFCMs can enter food by contact via a process called migration (Mezcua et al. 2012).

Studies in Korea and Japan revealed a heavy reliance on PTFCMs as plastic food containers (71.6 and 64.6\%), respectively (Japan Hygienic Olefin and Styrene Plastics Association, 2006; Korea Food and Drug Administration, 2007). However, limited studies are documented on PTFCMs in other regions, including in Malaysia, thus the present study is important to be carried out in evaluating their KAP of EDCs. 


\section{Samples}

\section{Materials and Methods}

A total of 150 university students from Universiti Malaysia Terengganu, Universiti Sultan ZainalAbidin, and Open University Malaysia, all three located in Kuala Terengganu. Among these students, 75 were studying science and 75 were non-science students.

\section{Survey Instrument}

The study comprised a cross-sectional survey for purposes of discovering KAP levels as well as frequency and patterns of PTFCMs usage, in addition to modulators affecting PTFCMs usage.

Data were collected data using an investigator-administered questionnaire completed with assistancefrom and in the presence-of the researcher. The questionnaire comprised five sections that included closedended, open-ended, filtered, contingent and matrix questions.

\section{Data Analysis}

The Statistical Package for Social Science (SPSS, Version 20.0) at significant differences set at $p<0.05$ was used in the data analysis.

\section{Validity and Reliability}

Inter-item correlations established reliability of results following the setting of Cronbach's alpha by a pilot test involving 30 university students. Knowledge scored $\alpha=0.877$, indicating good consistency and thus reasonable reliability as $\alpha$ was more than 0.7 (David de Vaus, 2002).

Demographic Profile of Respondents

\section{Results and Discussion}

Table 1 presents demographic profiles for all 150 respondents, including gender, age, race, current educational status, household income and courses of study.

Table 1. Demographic Profiles of Respondents

\begin{tabular}{|c|c|c|}
\hline Characteristics & Number of respondents $(n=150)$ & Percentage (\%) \\
\hline \multicolumn{3}{|l|}{ Gender } \\
\hline Male & 38 & 25.3 \\
\hline Female & 112 & 74.7 \\
\hline \multicolumn{3}{|l|}{ Age } \\
\hline Median $\left(Q_{1}, Q_{3}\right)$ & $23(20,25)$ & \\
\hline $18-20$ & 43 & 29.2 \\
\hline $21-23$ & 55 & 37.4 \\
\hline $24-26$ & 21 & 14.3 \\
\hline $27-29$ & 9 & 6.1 \\
\hline $30-32$ & 7 & 4.8 \\
\hline$>32$ & 12 & 8.2 \\
\hline \multicolumn{3}{|l|}{ Race } \\
\hline Malay & 104 & 69.3 \\
\hline Chinese & 40 & 26.7 \\
\hline Indian & 4 & 2.7 \\
\hline Other & 2 & 1.3 \\
\hline \multicolumn{3}{|c|}{ Current Educational Status } \\
\hline $\mathrm{PhD}$ & 11 & 7.3 \\
\hline MS & 37 & 24.7 \\
\hline $\mathrm{BS}$ & 66 & 44.0 \\
\hline Diploma & 36 & 24.0 \\
\hline \multicolumn{3}{|l|}{ Household income } \\
\hline$<\mathrm{RM} 1000$ & 35 & 24.5 \\
\hline RM1000-RM1999 & 31 & 21.7 \\
\hline RM2000-RM3999 & 38 & 26.5 \\
\hline RM4000-RM5999 & 24 & 16.8 \\
\hline RM6000-RM7999 & 6 & 4.2 \\
\hline$>$ RM8000 & 9 & 6.3 \\
\hline \multicolumn{3}{|l|}{ Course of Study } \\
\hline Science & 75 & 50.0 \\
\hline Non-science & 75 & 50.0 \\
\hline
\end{tabular}




\section{Knowledge}

'Knowledge' percent scores were low, with a median of $37.1 \%$. The majority of respondents $(84.0 \%)$ had a 'knowledge' level classified as poor (Figure 1). This outcome contradicted comparative studies by Kasemsup and Neesanan (2011) in which most respondents (67.5\%) scored medium knowledge levels and 8.5\% scored high levels. The contrast is most likely because the previous studies involved only PTFCMs while the present study included EDCs, which is a less known topic among the general population. Only $32.7 \%$ respondents knew that bisphenol-A (BPA) is an EDC, even though it is the most common EDC found in PTFCMs (Vandenberg et al. 2007). This finding suggests that general knowledge of EDCs is quite low.

Science and non-science students demonstrated a significant difference $(p<0.0001)$ in 'knowledge' scores as assessed by the Mann-Whitney test. Science students scored $42.9 \%$ for 'knowledge' compared to $31.4 \%$ for non-science students. Seven questions addressed factors that increase favourable conditions for EDC migration. Science students easily managed these specific questions because conditions for EDC and chemical migration have similar modulators that affect chemical reaction rates. For instance, high temperatures increase reaction rates for normal chemical processes and also account for increased levels of EDC migration (Arvanitoyannis and Bosnea, 2004).The present study also found a significant association between knowledge level and 'course of study' $(p<0.0001)$ as shown by Pearson chi-square, which suggests that respondent knowledge depends on educational background.

\section{Attitude}

Ninety percent of respondents scored 'fair' for 'attitude' levels with a mean of $69.2 \%$ (Figure 1).Our finding that 'attitude' scored higher than 'knowledge' concurs with a study by Kasemsup and Neesanan (2011). This result also suggests that university students are aware of adverse effects from PTFCMs and EDCs but require more knowledge about proper PTFCM usage. Similar to the just mentioned results, attitude scores for science students were significantly higher than for non-science students $(p<0.0001)$ (Mann-Whitney test).Pearson chi-squarenoted a significant association $(p<0.05)$ between 'attitude' and 'course of study'. Even though 'attitude' scores for both science and non-science students dropped to 'fair', science students scored significantly higher than non-science students, (70.8 vs. $65.4 \%)$, respectively. This infers that science students have slightly more sophisticated attitudes driven by higher levels of subject-related knowledge.

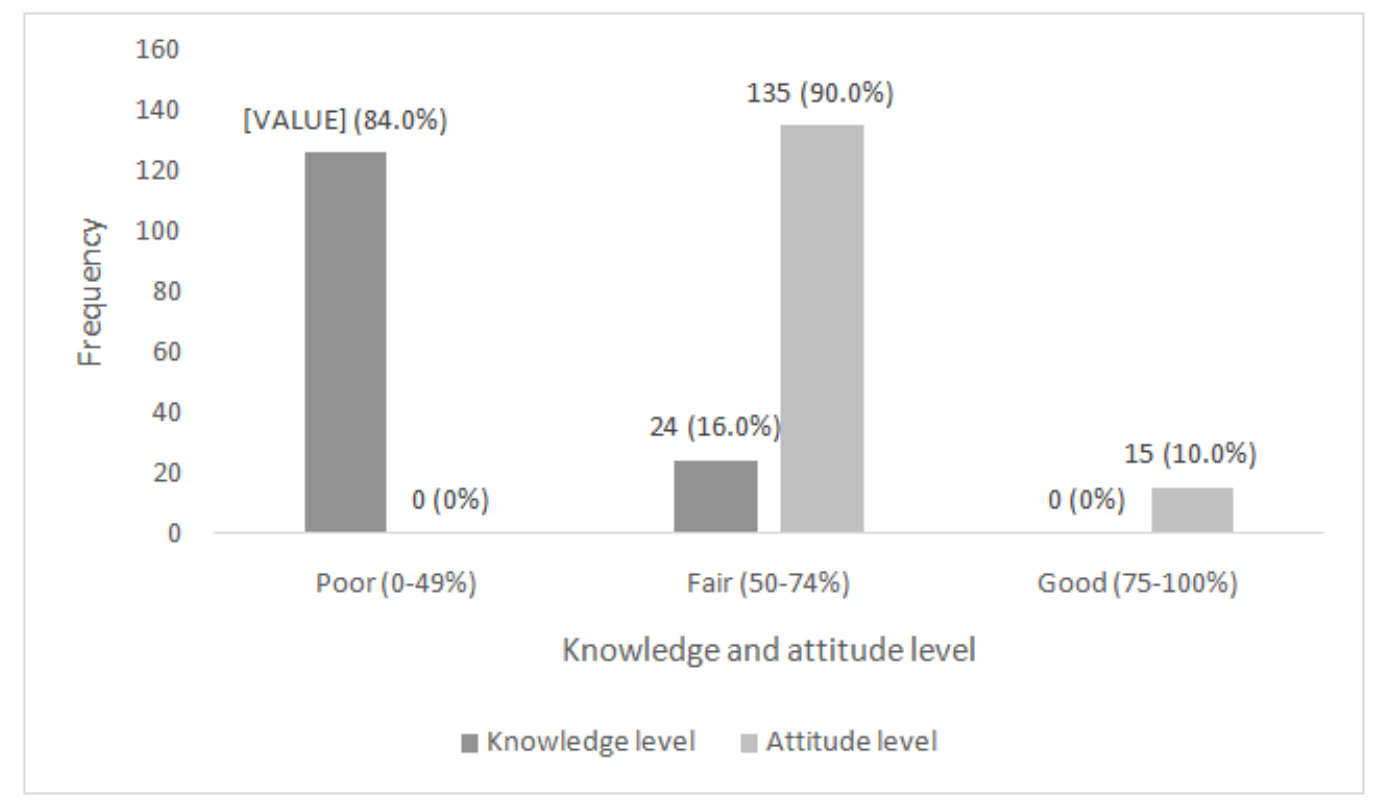

Figure 1. Knowledge and Attitude Levels

\section{Practice}

Ninety-six percent (96\%)of respondents acknowledged their use of PTFCMs, which reflects the normal trend reported by Kasemsup and Neesanan (2011) where 80\% of Thai participants used polystyrene, as also confirmed by Tukur et al. (2012) whose group reported that $80 \%$ of their British participants use the PET bottle. This study's findings align with previous studies even though the latters' findings only focused on one PTFCM type. Consequently, PTFCM usage trends, as reported in previous studies, would likely have approached our 96\% level if they had also assessed general PTFCM usage. 
Bottle usage is an unavoidable aspect of a university student's lifestyle. The present study found that $49.7 \%$ of respondents admitted using a polypropylene (PP) bottle or a polyethylene terephthalate (PET) bottle as the second most common choice (Table 2). PET usage in Greece was reported at $80 \%$ of all plastic bottles both used and manufactured for bottled water due to its desirable physical and chemical properties such as strength, transparency, light weight and ease of recycling (Diana and Dimitra, 2011). However, our respondents preferred the PP water bottle, probably due to its common reuse and convenience.

Table 2. Daily Bottle Usage

\begin{tabular}{|l|c|c|}
\hline Type of bottle & Frequency & Percentage (\%) \\
\hline Polyethylene terephthalate (PET) & 48 & 26.8 \\
\hline High density polyethylene (HDPE) & 3 & 1.7 \\
\hline Polyvinyl chloride (PVC) & 0 & 0 \\
\hline Low density polyethylene (LDPE) & 3 & 4.7 \\
\hline Polypropylene (PP) & 89 & 10.6 \\
\hline OTHER & 19 & 5.0 \\
\hline Not related/ unsure & 9 & 4.5 \\
\hline Non-plastic type & 8 & 100 \\
\hline Total & 179 & \\
\hline
\end{tabular}

In the present study, an open-ended question to ascertain information regarding other types of water bottle usage was applied. Nineteen (19) respondents used 'OTHER Type' (code 7): eight used Tritan ${ }^{\mathrm{TM}}$; $\operatorname{seven}$ used PC; and four used bottles without stating a plastic type. Nonetheless, PC should never be used as a water bottle. Malaysia even banned its use for the feeding of children and infants as of March 2012 (The Star Online, 2012). However, this legislation only focused on the susceptibility of children and infants to BPA, a PC monomer component. But BPA is also associated with adverse health effects in adult with respect to increased cardiovascular disease and diabetes (Lang et al. 2008). To the contrary, the Tritan ${ }^{\mathrm{TM}}$ water bottle is the recommended alternative to PC because it is BPA-free (Biron, 2012). The category for 'OTHER' bottle types provided no identifications, which shows irresponsibility on the part of some bottle manufacturers who provide inadequate information to bottle users. This is actually a serious matter since unlabelled bottles might not be safe should they contain substandard PC material.

Reponses for frequency of selected PTFCM usage (Table 3) indicated the use of polypropylene (PP) food containers at 50.99\%; polystyrene (PS) food container at $49.80 \%$; and carbonated canned beverages at $32.09 \%$. Although 'frequency' was tabulated as food usage with the assumption that respondents utilized PTFCMs for food intake, calculated PTFCMs usage cannot directly reflect food consumption, indicating a limitation of the present work. The present study data analysis was adapted to a report by Chee et al. (1996) where $<60 \%$ of frequency scores were classified as 'low' consumption. All classifications of PTFCMs usage for food and beverage consumption scored 'low' levels. However, the collective score is high if all nine PTFCMs were assessed as the sum of total for usage. Since the PP container is reusable because it is semi-rigid and can withstand high temperatures, this could account for PP being the most frequently used plastic in the present study (Hui \& Sherkat, 2005).

In 2008, the Consumer Association of Penang (CAP) advisor, Dr. T. Jayabalan, who is also a member of the National Poison Centre, encouraged consumers to avoid using plastic bags, polystyrene boxes and plastic cling wrap to package food due to the migration of harmful chemicals into the packaged food (Sung, 2010). Even though CAP had highlighted the issue for years before the present study, the score for food cling film usage was $36.44 \%$.

Table 3. Frequency Scores for Plastic Types of Food Contact Materials

\begin{tabular}{|l|c|c|c|}
\hline \multicolumn{1}{|c|}{ Plastic type of food contact material } & Science (\%) & Non-science (\%) & Overall (\%) \\
\hline PET bottled mineral water & 52.49 & 52.86 & 49.65 \\
\hline PET bottled carbonated water & 32.86 & 35.06 & 33.99 \\
\hline Plastic food cling wrap & 28.74 & 32.96 & 36.44 \\
\hline PP plastic food container & 49.03 & 47.08 & 50.99 \\
\hline PS plastic food container & 50.40 & 49.18 & 49.80 \\
\hline PS cutlery & 46.66 & 48.63 & 47.73 \\
\hline Canned-food & 33.54 & 34.75 & 34.13 \\
\hline Non-carbonated canned beverage & 31.83 & 37.93 & 35.00 \\
\hline Carbonated canned beverage & 28.83 & 35.14 & 32.09 \\
\hline
\end{tabular}

Table 4 lists usage patterns for PTFCMs. Collectively, 44.1\% of our respondents routinely left PET bottles inside their cars. When left in a car during hot weather, EDC leaching from PET bottles increases and the migration accelerates as temperatures rise along with exposure to UV radiation (Peiper, 2008). This 
chemical reaction worsens in equatorial zones such as Malaysia, which is hot and humid throughout most of the year with overall temperatures between 22 and $33^{\circ} \mathrm{C}$ (Gin, 2009). Moreover, 51.6\% of our respondents also used plastic cling film to wrap foodstuffs. EDCs from cling wrap films migrate into food much more when in direct contact compared to no direct contact (Chen et al. 2008). In addition, our respondents also reported keeping hot, acidic, oily food in plastics for long periods of time; all of which are factors that increase EDC migration (Helmrothet al. 2002; Muncke, 2009; Muncke, 2011).

Table 4.Usage Pattern Frequencies: PET bottles, Cling film, PP \& PS food containers

\begin{tabular}{|c|c|c|c|c|}
\hline \multirow[t]{2}{*}{ Practice } & \multicolumn{4}{|c|}{ Frequency (Percentage, \%) } \\
\hline & Never & 1-2 days per week & 3-5 days per week & 5-7 days per week \\
\hline \multicolumn{5}{|l|}{ PET bottle } \\
\hline Leaving inside car & $81(55.9)$ & $44(30.3)$ & $16(11.0)$ & $4(2.8)$ \\
\hline \multicolumn{5}{|l|}{ Food cling film } \\
\hline Wrap in contact with food & $60(48.4)$ & $43(34.7)$ & $13(10.5)$ & $8(6.5)$ \\
\hline Wrap without food contact & $53(42.7)$ & $46(37.1)$ & $18(14.5)$ & $7(5.6)$ \\
\hline Microwave with food & $93(75.0)$ & $19(15.3)$ & $12(9.7)$ & $0(0)$ \\
\hline \multicolumn{5}{|l|}{ PP food container } \\
\hline Holding hot food & $55(35.1)$ & $71(48.0)$ & $17(11.5)$ & $8(5.3)$ \\
\hline Holding acidic food & $77(52.0)$ & $52(35.1)$ & $17(11.5)$ & $2(1.4)$ \\
\hline Holding oily food & $37(25.0)$ & $69(46.6)$ & $32(21.6)$ & $10(6.8)$ \\
\hline $\begin{array}{l}\text { Holding food for long periods }(>5 \\
\text { hours) }\end{array}$ & $56(37.8)$ & $61(41.2)$ & $18(12.2)$ & $13(8.8)$ \\
\hline Holding hot food & $49(34.0)$ & $62(43.1)$ & $21(14.6)$ & $12(8.3)$ \\
\hline Holding acidic food & $90(62.5)$ & $37(25.7)$ & $12(8.3)$ & $5(3.5)$ \\
\hline Holding oily food & $34(23.6)$ & $77(53.5)$ & $23(16.0)$ & $10(6.9)$ \\
\hline $\begin{array}{l}\text { Holding food for long periods (>5 } \\
\text { hours) }\end{array}$ & $76(52.8)$ & $47(32.6)$ & $12(8.3)$ & $9(6.3)$ \\
\hline $\begin{array}{l}\text { Holding food for short periods }(\leq 5 \\
\text { hours) }\end{array}$ & $29(20.1)$ & $81(56.3)$ & $20(13.9)$ & $14(9.7)$ \\
\hline
\end{tabular}

\section{Most Influential Factors Prompting the Use of PTFCMs}

Modulating factors provide data that helps us understand motivations for PTFCM usage.Our respondents reported the following factors: low cost was the most influential factor $(21.6 \%)$; followed by lightweight $(20.3 \%)$; and ease of disposal with no need to clean $(19.7 \%)$. Customer purchasing behaviours can be quite complex and many factors influence buying-patterns with one of the most important being low price (Raulerson et al. 2009). Although price is not the only factor, in the case of PTFCMs it is highly significant, especially as manufacturing and transportation costs for plastics are low, which make PTFCMs far cheaper than other materials (Andrady \& Neal, 2009).

\section{Possible Types of EDC Exposure}

In addition to substances and plastic additives that migrate into food, other impurities from plastic ingredients might leach from PTFCMs. These are known as NIAS (Non-Intentionally Added Substance). It is estimated that NIAS comprise $>50 \%$ of such migrating compounds (Bradley et al. 2008). Unfortunately, these NIAS identities are not always identifiable (Grob, 2002). In a review by Geuekeet al. (2014), at least 119 known EDCs can leach from plastic food contact materials. The scenario will likely worsen as additional chemicals from PTFCMs are identified in the future, some of which might also have endocrine disruptive properties (Neltneret al. 2013).

People who use the PET bottle are subject to EDC chemical exposures. These toxins include BPA, formaldehyde, acetaldehyde, antimony, alkylphenols and a group of phthalates comprising dibutylphthalate (DBP), bis- (2-ethylhexyl) phthalate (DEHP) and benzylbutylphthalate (BBP) (Diana \&Dimitra, 2011; Guart et al. 2011; Bach et al. 2012; Elobied et al. 2012; Tukur et al. 2012). Plastic cling film exposes users to adipates, citrates and phthalates (Tsumura et al. 2002). A study by Goulas et al. (2007) found bis-(2-ethylhexyl) adipate (DEHA) in food wrapped in PVC cling film. Apart from styrene, a monomer that leaches from PS containers, additives such as dimethyl phthalate (DMP), 4-tert-octylphenol (OP), nonylphenol (NP), di-(2-ethylhexyl) adipate (DEHA) and bis-(2-ethylhexyl) phthalate (DEHP) migrations have also been reported (Ohno et al. 2001; Fasano et al. 2012). As for the PC bottle, BPA - a monomer used in the manufacture of PC - also migrates into foodstuffs (Cao and Corriveau, 2008). 


\section{Conclusion}

The present study demonstrates that the knowledge level of respondents regarding EDCs and PTFCMs is categorized as 'poor' (overall mean $=37.1 \%$ ). Moreover, their majority $(84.0 \%$ ) showed a 'poor' knowledge level and only $16.0 \%$ scored 'fair' while none scored 'good'. However, their 'attitude' scores averaged $69.2 \%$ and their majority was designated as 'fair' while none scored 'poor', 90.0\% scored 'fair' and $10.0 \%$ scored 'good'. Almost all respondents $(96.0 \%)$ used PTFCMs and most $(49.7 \%)$ commonly used a PP water bottle. 'Usage Patterns' that elevate EDC migration from PET bottles, food cling films, PS and PP food containers were also common. Hence, our findings indicate that student KAP levels need improvement, especially as numerous deleterious health effects are linked to EDCs. Government agencies and NGOs should combine their efforts to introduce educational programs with a view to minimize long-term morbidity and mortality by teaching appropriate knowledge and measures that can help avoid or at least reduce the public's exposure to EDCs.

Future studies could sample pregnant women and other normal working adults to further validate the general public's perspectives. Furthermore, PTFCMs not selected for the present study can be targeted for future assessments to include parchment paper and paper boxes that often have plastic linings as well as plastic bags used for take-away meals, plastic gloves used in the preparation of meals, plastic food thermo-boxes and many others. In addition, biochemical elements can be added such as the detection of EDCs in serum and urine samples. Such measures can inform a more complete appraisal of EDC exposure routes and also update our knowledge, attitude and practice data files with relevant biochemical data.

\section{References}

[1]. Andrady, A.L. and Neal, M.A. (2009). Applications and societal benefits of plastics. Philosophical Transactions of the Royal Society B, 364: 1977-1984.

[2]. Arvanitoyannis, I. and Bosnea, L. (2004). Migration of substances from food packaging materials to foods. Critical Reviews in Food Science and Nutrition, 44(2): 63-76.

[3]. Bach, C., Dauchy, X., Chagnon, M.C. and Etienne, S. (2012). Chemical compounds and toxicological assessments of drinking water stored in polyethylene terephthalate (PET) bottles: A source of controversy reviewed. Water Research, 46: 571-583.

[4]. Biron, M. (2012). Thermoplastics and Thermoplastic Composites (p. 886-887). Waltham: Elsevier Ltd.

[5]. Bradley, E., Driffield, M., Harmer, N., Oldring, P. and Castle, L. (2008). Identification of potential migrants in epoxy phenolic can coatings. International Journal of Polymer Analysis and Characterization, 13(3): 200-223.

[6]. Cao, X.L. and Corriveau, J. (2008). Migration of bisphenol-A from polycarbonate baby and water bottles into water under severe conditions. Journal of Agricultural and Food Chemistry, 56: 6378-6381.

[7]. Chee, S.S., Zawiah, H., Ismail, M.N. and Ng, K.K. (1996). Anthropometry, dietary patterns and nutrient intakes of Malaysian estate workers. Malaysia Journal of Nutrition, 2(2): 112-126.

[8]. Chen, M.L., Chen, J.S., Tang, C.L. and Mao, I.F. (2008). The internal exposure of Taiwanese to phthalate- An evidence of intensive use of plastic materials. Environment International, 34: 79-85.

[9]. Damstra, T., Barlow, S., Bergman, A., Kavlock, R.J. and KraakGeds, V.D. (2002).World Health Organization (WHO) (Sep.): Global assessment of the state-of-the-science of endocrine disruptors. Retrieved 02 Feb. 2015 from: http://www.who.int/ipcs/publications/endocrine_disruptors/endocrine_disruptors/en/

[10]. David de Vaus (2002). Analysing Social Science Data: 50 key Problems in Data Analysis, (p. 20). Thousand Oaks: SAGE Publications Inc.

[11]. Diana, A. and Dimitra, V. (2011). Alkylphenols and phthalates in bottled waters. Journal of Hazardous Materials, 185: $281-286$.

[12]. Fasano, E., Bono-Blay, F., Cirillo, T., Montouri, P. and Lacorte, S. (2012). Migration of phthalates, alkylphenols, bisphenol A and di(2-ethylhexyl)adipate from food packaging. Food Control, 27: 132-138.

[13]. Food and Agriculture Organization (FAO). (2014). Guidelines for assessing nutrition-related Knowledge, Attitudes and Practices. Retrieved 27 Feb. 2015 from: http://www.fao.org/docrep/019/i3545e/i3545e00

[14]. Geueke, B., Wgner, C.C. and Muncke, J. (2014). Food contact substances and chemicals of concern: a comparison of inventories. Food Additives \& Contaminants, Part A, 31(8): 1438-1450.

[15]. Gin, O.K. (2009). Historical Dictionary of Malaysia (p. 1). Plymouth: The Scarecrow Press Inc.

[16]. Goulas, A.E., Zygoura, P., Karatapanis, A., Georgantelis, D. and Kontominas, M.G. (2007). Migration of di(2-ethylhexyl) adipate and acetyltributyl citrate plasticizers from food-grade PVC film into sweetened sesame paste (halawatehineh): kinetic and penetration study. Food and Chemical Toxicology, 45: 585-591.

[17]. Grob, K. (2002). Comprehensive analysis of migrates from food-packaging materials: a challenge. Food Additives \& Contaminants, 19:185-191.

[18]. Guart, A., Bono-Blay, F., Borrel, A. and Lacorte, S. (2011). Migration of plasticizers phthalates, bisphenol-A and alkylphenols from plastic containers and evaluation of risk. Food Additives and Contaminants, 28(5): 676-685.

[19]. Guart, A. Wagner, M., Mezquida, A., Lacorte, S., Oehlamnn, J. and Borrell, A. (2013). Migration of plasticisers from Tritan ${ }^{\mathrm{TM}}$ and polycarbonate bottles and toxicological evaluation. Food Chemistry 141: 373-380.

[20]. Helmroth, E., Rijk, R., Dekker, M. and Jongen, W. (2002). Predictive modelling of migration from packaging materials into food products for regulatory purposes. Trends in Food Science \& Technology, 13: 102-109.

[21]. Hui, Y. H. and Sherkat, F. (eds.) (2005). Handbook of food science, technology, and engineering. Vol. 4 (p. 131-135). Boca Raton: CRC Press.

[22]. Japan Hygienic Olefin and Styrene Plastics Association (JHOSPA). (2006). Technical Report. Japan: survey report on materials used for food containers in Japan.

[23]. Kasemsup, R. and Neesanan, N. (2011). Knowledge, attitudes and practices relating to plastic containers for food and drinks. Journal of the Medical Association of Thailand, 94(3): 121-125.

[24]. Korea Food and Drug Administration (KFDA). (2007). Public information brochure on packaging and tools for food. Retrieved 05 Mar 2015 from: http://fse.foodnara.go.kr/pack/z05_buss/buss_public_view.jsp?pd_idx=33 
[25]. Lang, I.A., Galloway, T.S., Scarlett, A., Henley, W.E., Depledge, M., Wallace, R.B. and Melzer, D. (2008). Association of urinary Bisphenol-A concentration with medical disorders and laboratory abnormalities in adults. JAMA, 300: 1303-1310.

[26]. Mezcua, M., Martinez-Uroz, M.A., Gomez-Ramos, M.M., Gomez, M.J., Navas, J.M. and Fernandez-Alba, A.R. (2012). Analysis of synthetic endocrine-disrupting chemicals in food: A review. Talanta, 100: 90-106.

[27]. Muncke, J. (2009). Exposure to endocrine disrupting compounds via the food chain: Is packaging a relevant source? Science of the Total Environment, 407(16): 4549-4559.

[28]. Muncke, J. (2011). Endocrine disrupting chemicals and other substances of concern in food contact materials: An updated review of exposure, effect and risk assessment. Journal of Steroid Biochemistry \& Molecular Biology, 127: 118-127.

[29]. Neltner, T.G., Alger, H.M., Leonard, J.E. and Maffini, M.V. (2013). Data gaps in toxicity testing of chemicals allowed in food in the United States. Reproductive Toxicology, 42:85-94.

[30]. Ohno, K., Azum, Y., Nakano, S., Kobayashi, T., Hirano, S., Nobuhara, Y. and Yamada, T. (2001). Assessment of styrene oligomers eluted from polystyrene-made food containers for estrogenic effects in in vitro assays. Food and Chemical Toxicology, 39: 1233-1241.

[31]. Patisaul, H.B. and Adewale, H.B. (2009). Long-term effects of environmental endocrine disruptors on reproductive physiology and behavior. Frontiers in Behavioural Neuroscience, 3:1-18.

[32]. Peiper, H. (2008). Create a Miracle with Hexagonal Water: The Simple Solution for Vital Health and Longevity (p. 36). Sheffield: ATN Publishing.

[33]. Raulerson, P., Malraison, J. and Leboyer, A. (2009). Building Routes to Customers: Proven Strategies for Profitable Growth (p.96). Bellevue: Springer Science \& Business Media.

[34]. Shaw, I. (ed.) 2009. Endocrine-Disrupting Chemicals in Food (p. 103). Cambridge: Woodhead Publishing Limited.

[35]. Sungur, S., Koroglu, M. and Ozkan, A. (2014). Determination of bisphenol-A migrating from canned food and beverages in markets. Food Chemistry, 142: 87-91.

[36]. Sung, G. B. 2010. Ban on plastic bags usage: is it a right move? An empirical study on consumer perception and practice. MS Thesis, Universiti Sains Malaysia, Penang.

[37]. The Star Online. (March 2012). BPA now banned. Retrieved on13 Dec, 2012from: http://www.thestar.com.my/news/nation/2012/03/01/bpa-bottles-now-banned/

[38]. Tsumura, Y., Ishimitsu, S., Kaihara, A., Yoshii, K., Tonogai, Y. (2002). Phthalate adipates, citrate and some other plasticizers detected in Japanese retail foods: a survey. Journal of Health Science, 48: 493-502.

[39]. Tukur, A. Sharp, L. Stern, B., Tizaoui, C. and Benkreira, H. (2012). PET bottle use patterns and antimony migration into bottled water and soft drinks: the case of British and Nigerian bottles. Journal of Environmental Monitoring,14: 1237-1247.

[40]. Vandenberg, L.N., Hauser, R., Marcus, M., Olea, N. and Welshons, W.V. (2007). Human exposure to bisphenol-A (BPA). Reproductive Toxicology, 24: 139-177. 